\section{Noninvasive prediction of carotid artery atherosclerosis by multiple abdominal fat indices measured via ultrasonography}

\author{
Mohammed Hazem ${ }^{1,2}$, Mahmoud Elsamman ${ }^{3}$, Shamardan Bazeed ${ }^{4}$, Mohammed Zaki ${ }^{2}$ \\ 'Department of Surgery, Faculty of Medicine, King Faisal University, Al-hofuf, Saudi Arabia; \\ ${ }^{2}$ Department of Radiology, Faculty of Medicine, Sohag University, Sohag; ${ }^{3}$ Gastroenterology \\ Division, Internal Medicine Department, Faculty of Medicine, Sohag University, Sohag; \\ ${ }^{4}$ Department of Tropical Medicine and Gastroenterology, Faculty of Medicine, South Valley \\ University, Qena, Egypt
}

Purpose: The purpose of this study was to evaluate the efficiency of multiple abdominal fat indices as measured via ultrasonography for predicting the presence and severity of carotid artery atherosclerosis and to compare the predictive capacity of ultrasonographic measurements to that of anthropometric measurements.

Methods: A total of 92 patients were included in this study. All participants underwent clinical and laboratory assessments, and anthropometric measurements were obtained. Ultrasound examinations were performed to measure the values of all abdominal fat indices and the intimamedia thickness, as well as to detect the presence of atherosclerotic plaques. Univariate and multivariate logistic regression analyses were performed.

Results: In the multivariate analysis, significant associations were detected between carotid artery atherosclerosis and posterior right perinephric fat thickness (PRPFT) (hazard ratio [HR], 15.23; $P<0.001)$, preperitoneal fat thickness (PPFT) (HR, 4.31; $P=0.003)$, visceral adipose tissue volume (VAT) (HR, 7.61; $P<0.001)$, visceral fat thickness (VFT) (HR, 8.84; $P<0.001)$, the ratio of VFT to subcutaneous fat thickness (VFT/SCFT) (HR, 9.39; $\mathrm{P}<0.001)$, and waist-to-height ratio (WHtR) (HR, 2.65; $P=0.046)$. In the multivariate analysis, significant associations were also detected between carotid artery plaque and PRPFT (HR, 7.09; $\mathrm{P}<0.001)$, the abdominal wall fat index (AFI) (HR, 3.58; $\mathrm{P}=0.010)$, and VFT/SCFT (HR, 4.17; $\mathrm{P}=0.006)$.

Conclusion: Many abdominal fat indices as measured by ultrasound were found to be strong predictors of carotid artery atherosclerosis, including PRPFT, VFT/SCFT, VFT, VAT, PPFT, and WHtR. Moreover, PRPFT, VFT/SCFT, and AFI were identified as strong predictors of the presence of carotid artery plaque.

Keywords: Posterior perinephric fat; Abdominal fat thickness; Abdominal ultrasound; Anthropometric measurements; Carotid artery atherosclerosis

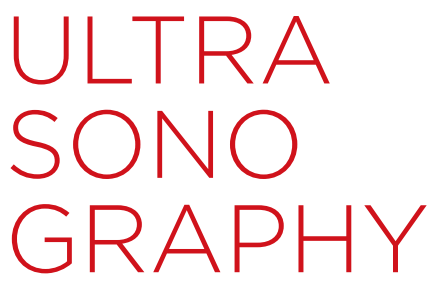

\section{ORIGINAL ARTICLE}

https://doi.org/10.14366/usg.20109 pISSN: 2288-5919 • elSSN: 2288-5943 Ultrasonography 2021;40:366-377

Received: July 15, 2020

Revised: October 8, 2020

Accepted: October 24, 2020

Correspondence to:

Mohammed Hazem, MD, Department of Surgery, Faculty of Medicine, King Faisal University, P.O. Box 400, Al-Ahsa 31982, Saudi Arabia

Tel. +966-135897802

Fax. +966-5801243

E-mail: mabdulghony@kfu.edu.sa, Mohamedhazem73@yahoo.com

This is an Open Access article distributed under the terms of the Creative Commons Attribution NonCommercial License (http://creativecommons.org/ licenses/by-nc/4.0/) which permits unrestricted noncommercial use, distribution, and reproduction in any medium, provided the original work is properly cited.

Copyright @ 2021 Korean Society of Ultrasound in Medicine (KSUM)

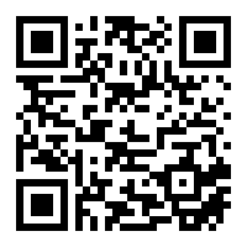

How to cite this article:

Hazem M, Elsamman M, Bazeed S, Zaki M Noninvasive prediction of carotid artery atherosclerosis by multiple abdominal fat indices measured via ultrasonography. Ultrasonography. 2021 Jul;40(3):366-377. 


\section{Introduction}

Atherosclerosis is a complex chronic disease [1] that is considered one of the most important preventable causes of ischemic stroke [2]. The first structural abnormality indicative of carotid artery atherosclerosis is an increase in intima-media thickness (IMT) [3]. Obesity has been shown to be one of the main factors contributing to atherosclerosis $[4,5]$. Moreover, visceral fat is regarded as an endocrine organ [6-8]. Like visceral fat, perirenal fat is metabolically active, and it has been demonstrated to be an independent predictor of cardiovascular disease risk [9-11].

The release of fatty acids and cytokines from adipose tissue into the circulation is the most widely accepted theory behind the association between abdominal fat and the development of carotid atherosclerosis [12].

Multiple indices of abdominal obesity exist, but which is the best discriminator of cardiovascular risk factors is still under debate [13]. Among anthropometric measurements, waist circumference (WC) has been found to be more strongly associated with subclinical atherosclerosis than is body mass index (BMI) [14-16]. However, WC showed a weaker association with carotid atherosclerosis than did visceral fat thickness (VFT) [17]. Among the various abdominal fat indices, the role of the posterior perinephric fat as a predictor of carotid atherosclerosis needs to be clarified.

The standard techniques used to quantify abdominal fat are computed tomography (CT) and magnetic resonance imaging (MRI) [18]. Nevertheless, these two modalities have major limitations and disadvantages, including cost, exposure to high doses of radiation, and technical concerns [19]. Several studies have compared the results obtained using CT or MRI to those obtained via ultrasound in the quantification of visceral fat, and they concluded that measurements obtained via ultrasonography were strongly correlated with those obtained via CT [18]. In addition, ultrasonography has been established as a noninvasive technique for the early detection of carotid atherosclerosis [3]. Several ultrasound measurements and ratios have been used as predictors of carotid atherosclerosis, but to the best of our knowledge, very few studies have examined the posterior perinephric fat as a predictor of this condition.

In the current study, we aimed to assess abdominal fat indices (as measured by ultrasonography) and anthropometric measurements as potential predictors of carotid atherosclerosis.

\section{Materials and Methods}

\section{Study Design}

This prospective study was approved by our institutional review board and the relevant committee of ethics (IRB no.: 129/2018), in accordance with the Declaration of Helsinki. All included participants provided written informed consent. We conducted this study between October 2018 and October 2019. It included 92 participants from the outpatient clinic of the internal medicine department of our institution, all of whom were referred for abdominal ultrasonography, were aged $>18$ years, agreed to participate in this study, and did not meet any exclusion criteria. Those criteria excluded participants with BMI $>40 \mathrm{~kg} / \mathrm{m}^{2}$, with chronic debilitating diseases (advanced cardiac, renal, or hepatic diseases), who were taking antilipidemic drugs, or who had a history of abdominal or bariatric surgery.

\section{Participant Assessment}

All participants were clinically assessed, which included historytaking, physical examination, and blood pressure measurements using standard criteria. Serum blood glucose levels and the lipid profile were assessed for each participant.

\section{Anthropometric Measurements}

Weight and height were measured, and then BMI was calculated. Hip circumference $(\mathrm{HC})$ was measured over the undergarments at the point of maximal gluteal protuberance. WC was measured in the standing position at the end of expiration, midway between the lower border of the last rib and the iliac crest. The waist-to-hip ratio (WHR) was calculated by dividing WC by HC (both in centimeters). The waist-to-height ratio (WHtR) was obtained by dividing WC by the height (both in centimeters). Measurements were obtained twice, and the average of the two measurements was used for the subsequent analyses.

\section{Abdominal Fat Thickness Measurements via Ultrasound}

Examination was done by a single radiologist with 14 years of experience using constant settings and a high-resolution ultrasound system (Aplio 500, Toshiba, Tokyo, Japan). The participants were examined in the supine position with a 3.5-MHz convex array probe and a $10-\mathrm{MHz}$ linear-array probe; all images were obtained at the end of expiration to avoid the effects of respiration, with light compression of the abdominal wall to avoid underestimation of the subcutaneous fat thickness (SCFT). The following measurements were made. First, posterior right perinephric fat thickness (PRPFT), the maximum fat thickness of the posterior right renal wall, was measured in the posterior right perinephric space [17]. In this study, we used PRPFT because it has been validated in previous research [20] (Fig. 1A). Next, SCFT was defined as the minimum fat thickness between the linea alba and the fat-skin interface, and it was measured between the umbilicus and the xiphoid process (Fig. 1B). 
Preperitoneal fat thickness (PPFT) was measured as the maximum fat thickness between the linea alba and the upper surface of the liver (Fig. 2A). The next measurement was the maximum distance between the inner aspect of the rectus abdominis muscle and the posterior aortic wall; this measurement was made $1 \mathrm{~cm}$ above the umbilicus in a line perpendicular to the aorta [21] (Fig. 2B). The distance between the splenic vein and the inner aspect of the abdominal muscle was also measured [17] (Fig. 3A). Next, the abdominal wall fat index (AFI) was obtained by dividing the PPFT by the SCFT [19]. Visceral adipose tissue volume (VAT) was calculated using the following equation: VAT $=9.008+1.191 \times$ (the distance between the splenic vein and the inner aspect of the abdominal muscle [in mm]) $+0.987 \times$ (the distance between the aortic posterior wall and the inner aspect of the abdominal muscle on the umbilicus [in $\mathrm{mm}])+3.644 \times$ (the thickness of the fat layer of the posterior right renal wall [in mm]) [22]. Three measurements were made, and the average was calculated; the intraobserver variability ranged from $1.2 \%$ to $1.6 \%$. VFT was defined as the distance between the inner aspect of the rectus abdominis muscle and the anterior wall of the aorta, measured perpendicular to the aorta [22] (Fig. 3B). The final measurement obtained was the VFT/SCFT ratio.

\section{Carotid Doppler Ultrasonography}

Carotid Doppler ultrasound examinations were performed by the same radiologist using the same ultrasound system with a $10-\mathrm{MHz}$ linear-array probe. The participants were examined in the supine

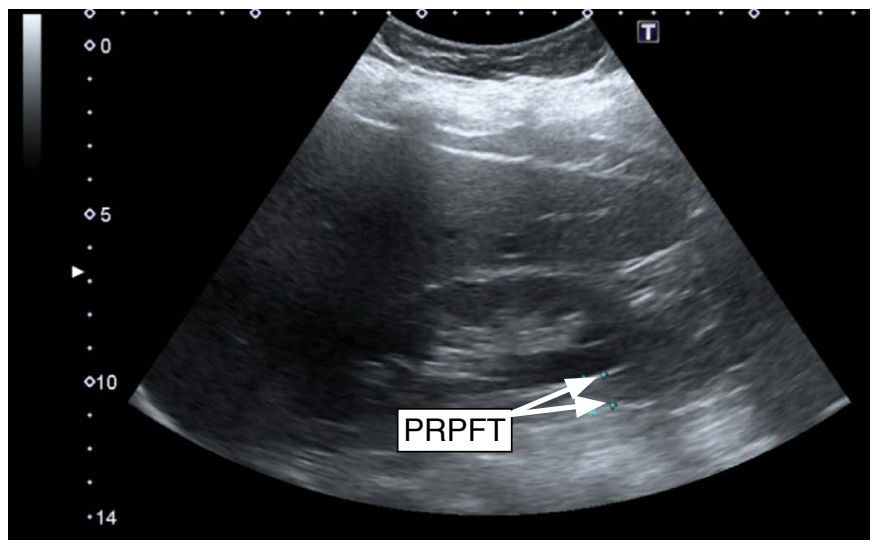

A

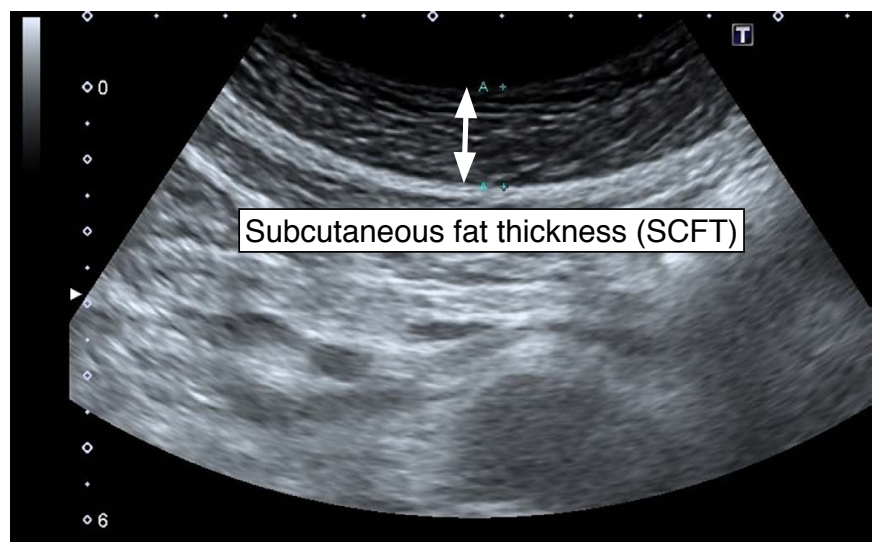

B

Fig. 1. Abdominal ultrasonography of a 58-year-old woman.

A. The thickness of the posterior right perinephric fat, is approximately $9.5 \mathrm{~mm}$. B. The minimum subcutaneous fat thickness is approximately $13.8 \mathrm{~mm}$. PRPFT, posterior right perinephric fat thickness.

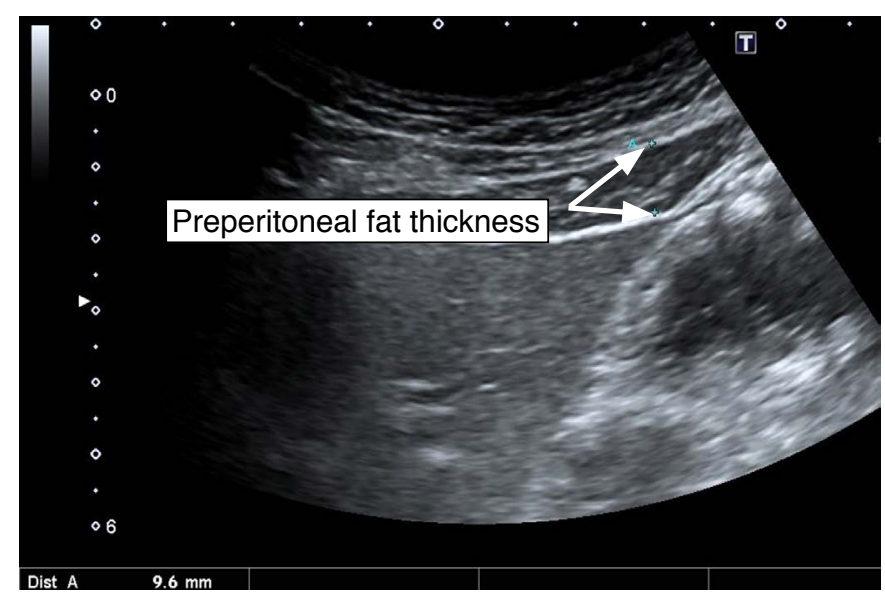

A

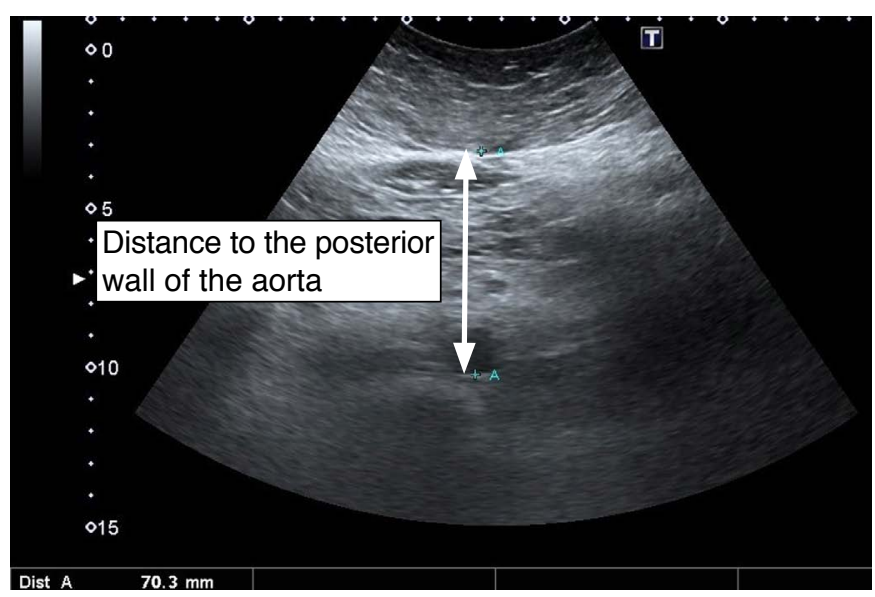

B

Fig. 2. Abdominal ultrasonography of a 62-year-old woman.

A. The preperitoneal fat thickness is approximately $9.6 \mathrm{~mm}$. B. The thickness from the posterior wall of the aorta to the inner surface of the abdominal muscle, is approximately $70.3 \mathrm{~mm}$. 


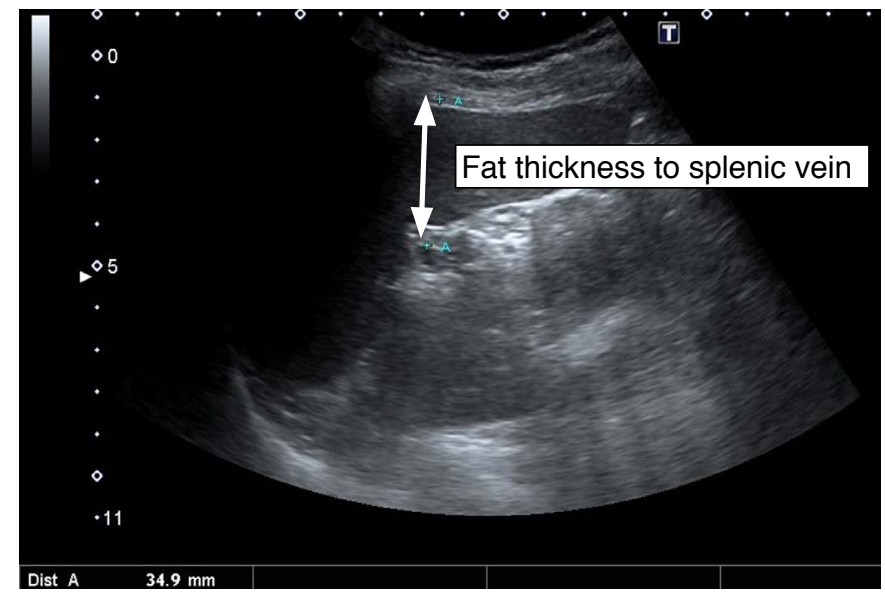

A

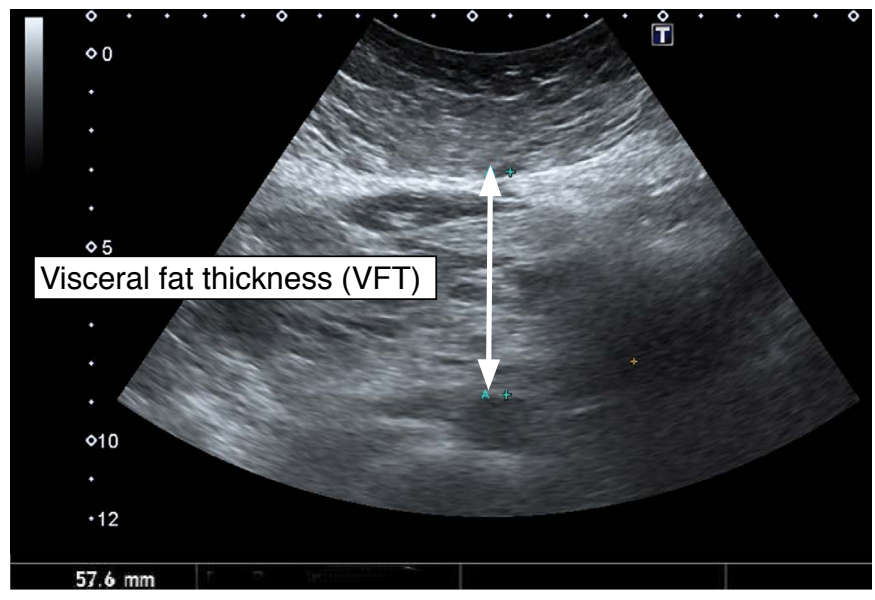

B

Fig. 3. Abdominal ultrasonography of a 48-year-old man.

A. The fat thickness from the splenic vein to the inner surface of the abdominal muscle, measuring approximately $34.9 \mathrm{~mm}$. B. Visceral fat thickness, which is the thickness from the anterior wall of the aorta to the inner surface of the abdominal muscle, measuring approximately $57.6 \mathrm{~mm}$.

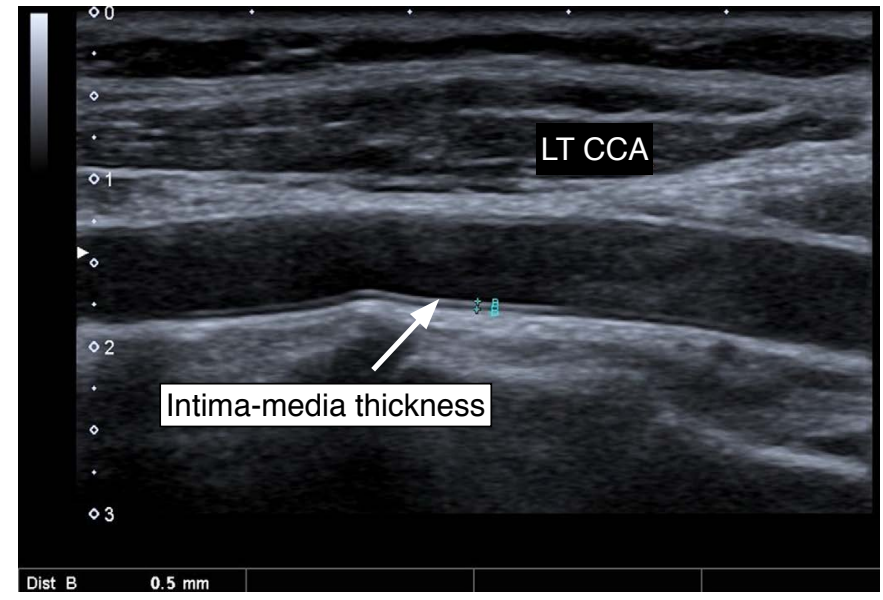

A

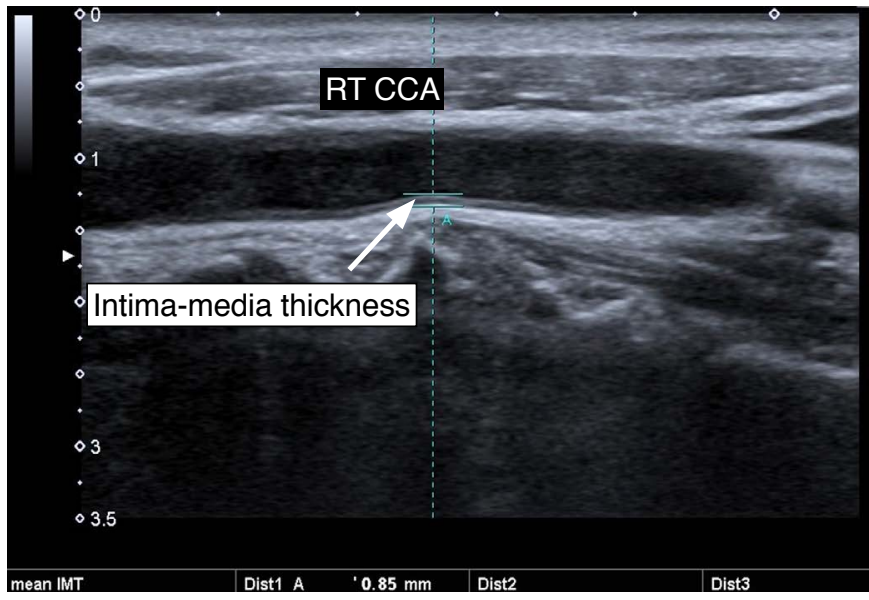

Fig. 4. Ultrasonography of the left (LT CCA) and right common carotid arteries (RT CCA) of a 48-year-old man on a longitudinal scan showing the intima-media thickness.

The thickness is approximately $0.5 \mathrm{~mm}(\mathrm{~A})$ and $0.85 \mathrm{~mm}(\mathrm{~B})$.

position, with the head elevated and slightly directed toward the opposite side of the examined carotid artery. The examination began with the measurement of IMT. Measurements were repeated three times, at the thickest point over $10 \mathrm{~mm}$ of uniform length in the far wall of the bilateral common carotid arteries in the $20 \mathrm{~mm}$ before the carotid bulb, without any areas of focal thickening (that is, plaque-free areas) (Fig. 4). From the three measurements on each side, the average IMT was calculated according to the European Society of Hypertension and the European Society of Cardiology guidelines [23]. In these guidelines, an IMT $>0.9 \mathrm{~mm}$ is considered abnormal (Fig. 4), and carotid plaque is defined as either an IMT $\geq 1.5 \mathrm{~mm}$ or a focal increase in thickness of $0.5 \mathrm{~mm}$ or $50 \%$ of the surrounding carotid IMT value (Fig. 5). The intraobserver variability ranged from $1.4 \%$ to $1.7 \%$.

\section{Statistical Analysis}

Descriptive statistics were presented using either numbers and percentages or means and standard deviations, as appropriate. The comparison between IMT among the baseline characteristics of participants was conducted using the Fisher exact test or the independent $t$ test, as appropriate. P-values $<0.05$ were considered to indicate statistical significance. A univariate and multivariate 


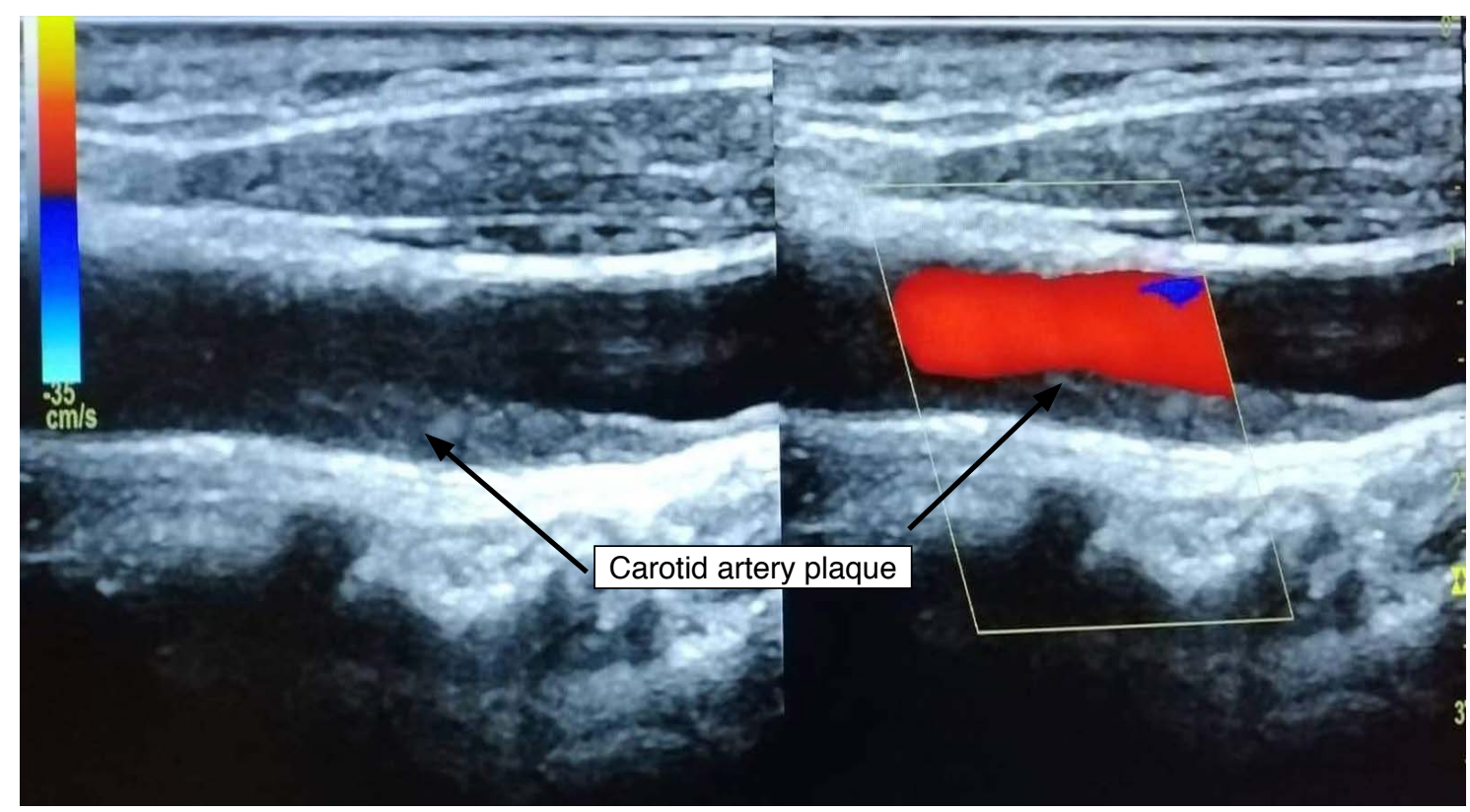

Fig. 5. Color Doppler ultrasound of the right common carotid artery of a 62-year-old woman on a longitudinal scan. The image on the right is a B-mode scan of the artery showing a large plaque partially obstructing the common carotid artery. The image on the left is a color Doppler scan showing blood flow within the artery and confirming the large size of the plaque.

regression analysis was also conducted to predict the effects of the risk factors and the degree of IMT; odds ratios along with 95\% confidence intervals (95\% Cls) were reported. Univariate and multivariate analyses were also carried out regarding the associations of the presence of a plaque or plaques with abdominal fat area thickness and anthropometric measurements. All statistical data analyses were performed using SPSS version 21 for Windows (IBM Corp., Armonk, NY, USA).

\section{Results}

In this prospective study, we enrolled 92 participants aged between 39 and 70 years (mean age, 57.72 \pm 7.32 years), with a male-tofemale ratio of approximately 2.4 to 1 . Table 1 presents the baseline characteristics of the study population. The difference between normal and atherosclerotic arteries was significant with regard to mean PRPFT $(P<0.001)$, PPFT $(P<0.001)$, VFT $(P<0.001)$, VFT/SCFT $(P<0.001)$, VAT $(P<0.001)$, and SCFT $(P=0.041)$, while it did not differ significantly with regard to AFI (Table 2). Of the anthropometric measurements, significant associations were detected between carotid artery atherosclerosis and both mean WC $(P=0.046)$ and mean HC ( $P=0.009)$, while no significant associations were detected with other anthropometric measurements. Only a few indices showed significant associations with the presence of carotid artery plaque (Table 3). These associations were significant with regard to mean PRPFT $(P<0.001)$, VFT/SCFT $(P=0.004)$, and HC $(P=0.026)$.
No significant association was detected with any other abdominal or anthropometric index.

The results of univariate and multivariate regression analysis of possible indices predictive of carotid artery atherosclerosis were provided in Table 4. Regarding the abdominal fat indices, many variants showed a significant association with carotid artery atherosclerosis. For participants with SCFT $>21.3 \mathrm{~mm}$, the risk of carotid atherosclerosis was 3.27 times higher than among participants with SCFT $\leq 21.3 \mathrm{~mm}$ (crude odds ratio [OR], 3.27; 95\% $\mathrm{Cl}, 1.31$ to $8.16 ; \mathrm{P}=0.011$ ), but after adjustment in the multivariate analysis, the risk did not differ significantly. Furthermore, among participants with PPFT $>10.8 \mathrm{~mm}$, the risk of carotid artery atherosclerosis was 4.45 times higher than among participants with PPFT $\leq 10.8 \mathrm{~mm}$ (crude OR, 4.45; 95\% Cl, 1.77 to 11.21 ; $\mathrm{P}=0.001$ ); in the multivariate analysis, the risk decreased to 4.31 times higher (adjusted OR [AOR], 4.31; 95\% Cl, 1.67 to $11.12 ; \mathrm{P}=0.003$ ). Similarly, for participants with PRPFT $>11.2 \mathrm{~mm}$, the risk of carotid artery atherosclerosis was 16.62 times higher than among those with PRPFT $\leq 11.2 \mathrm{~mm}$ (crude OR, 16.62; $95 \% \mathrm{Cl}, 5.69$ to 48.53; $P<0.001)$; in the multivariate analysis, the risk decreased to 15.23 times higher (AOR, 15.23; 95\% Cl, 4.99 to 46.24; $\mathrm{P}<0.001$ ).

In addition, the risk of carotid artery atherosclerosis was higher for individuals with the following abdominal fat measurements relative to their counterparts: VAT $>176 \mathrm{~mm}^{3}$ (crude OR, 8.26; $95 \% \mathrm{Cl}, 3.09$ to $22.12 ; \mathrm{P}<0.001 ; \mathrm{AOR}, 7.61 ; 95 \% \mathrm{Cl}, 2.70$ to $21.43 ; \mathrm{P}<0.001)$, VFT $>62.1 \mathrm{~mm}$ (crude $O R, 9.98 ; 95 \% \mathrm{Cl}, 3.67$ to $27.12 ; \mathrm{P}<0.001$; 
Table 1. Baseline characteristics of participants according to sex

\begin{tabular}{|c|c|c|c|c|}
\hline Variable & Total $(n=92)$ & Male $(n=64)$ & Female $(n=28)$ & P-value ${ }^{a)}$ \\
\hline \multicolumn{5}{|l|}{ Qualitative variables ${ }^{\text {b) }}$} \\
\hline Diabetes mellitus & $40(43.5)$ & $25(39.1)$ & $15(53.6)$ & 0.254 \\
\hline Hypertension & $55(59.8)$ & $35(54.7)$ & $20(71.4)$ & 0.168 \\
\hline Smoking & $60(65.2)$ & $54(84.4)$ & $6(21.4)$ & $<0.001$ \\
\hline Peripheral vascular disease & $22(23.9)$ & $16(25.0)$ & $6(21.4)$ & 0.796 \\
\hline \multicolumn{5}{|l|}{ Quantitative variables ${ }^{c}$} \\
\hline Age (year) & $57.72 \pm 7.32$ & $58.53 \pm 6.59$ & $55.93 \pm 8.61$ & 0.112 \\
\hline Total cholesterol (mg/dL) & $223.41 \pm 45.72$ & $220.82 \pm 43.91$ & $229.41 \pm 49.91$ & 0.412 \\
\hline $\mathrm{TG}(\mathrm{mg} / \mathrm{dL})$ & $132.31 \pm 30.91$ & $130.73 \pm 31.92$ & $135.91 \pm 28.93$ & 0.463 \\
\hline LDL-C (mg/dL) & $144.33 \pm 40.71$ & $141.91 \pm 40.40$ & $149.83 \pm 41.61$ & 0.392 \\
\hline $\mathrm{HDL}-\mathrm{C}(\mathrm{mg} / \mathrm{dL})$ & $46.30 \pm 7.56$ & $46.91 \pm 7.23$ & $44.72 \pm 8.17$ & 0.186 \\
\hline Height (cm) & $165.32 \pm 7.85$ & $168.43 \pm 6.40$ & $158.14 \pm 5.90$ & $<0.001$ \\
\hline Weight (kg) & $81.83 \pm 11.94$ & $81.93 \pm 12.61$ & $81.63 \pm 10.62$ & 0.917 \\
\hline $\operatorname{BMI}\left(\mathrm{kg} / \mathrm{m}^{2}\right)$ & $29.91 \pm 3.65$ & $28.82 \pm 3.43$ & $32.51 \pm 2.67$ & $<0.001$ \\
\hline$W C(\mathrm{~cm})$ & $104.94 \pm 10.74$ & $103.22 \pm 10.93$ & $108.92 \pm 9.32$ & 0.019 \\
\hline $\mathrm{HC}(\mathrm{cm})$ & $108.23 \pm 11.63$ & $105.51 \pm 11.92$ & $114.30 \pm 7.72$ & 0.001 \\
\hline WHR & $0.97 \pm 0.05$ & $0.98 \pm 0.04$ & $0.95 \pm 0.05$ & 0.012 \\
\hline $\mathrm{WHtR}$ & $0.64 \pm 0.06$ & $0.61 \pm 0.06$ & $0.69 \pm 0.04$ & $<0.001$ \\
\hline PRPFT (mm) & $12.05 \pm 2.03$ & $11.13 \pm 2.02$ & $12.24 \pm 2.08$ & 0.573 \\
\hline SCFT (mm) & $21.91 \pm 5.03$ & $20.92 \pm 4.73$ & $24.42 \pm 4.96$ & 0.002 \\
\hline PPFT (mm) & $11.43 \pm 1.73$ & $11.14 \pm 1.76$ & $12.23 \pm 1.42$ & 0.005 \\
\hline $\mathrm{VFT}(\mathrm{mm})$ & $65.79 \pm 15.02$ & $63.28 \pm 15.52$ & $71.53 \pm 12.97$ & 0.016 \\
\hline $\mathrm{VFT} / \mathrm{SCFT}$ & $3.02 \pm 0.47$ & $3.04 \pm 0.46$ & $2.99 \pm 0.49$ & 0.721 \\
\hline $\mathrm{AFI}$ & $0.57 \pm 0.12$ & $0.59 \pm 0.12$ & $0.55 \pm 0.11$ & 0.235 \\
\hline $\operatorname{VAT}\left(\mathrm{mm}^{3}\right)$ & $179.21 \pm 27.36$ & $176.72 \pm 28.12$ & $184.99 \pm 25.23$ & 0.184 \\
\hline Right IMT (mm) & $0.96 \pm 0.15$ & $0.97 \pm 0.15$ & $0.92 \pm 0.16$ & 0.211 \\
\hline Left IMT (mm) & $0.97 \pm 0.15$ & $0.98 \pm 0.14$ & $0.93 \pm 0.17$ & 0.169 \\
\hline
\end{tabular}

Values are presented as number (\%) or mean \pm SD.

TG, triglyceride; LDL-C, low-density lipoprotein cholesterol; HDL-C, high-density lipoprotein cholesterol; BMI, body mass index; WC, waist circumference; HC, hip circumference; WHR, waist-to-hip ratio; WHtR, waist-to-height ratio; PRPFT, posterior right perinephric fat thickness; SCFT, subcutaneous fat thickness; PPFT, preperitoneal fat thickness; VFT, visceral fat thickness; VFT/SCFT, ratio of visceral fat thickness to subcutaneous fat thickness; AFI, abdominal wall fat index; VAT, visceral adipose tissue volume; IMT, intimamedia thickness; SD, standard deviation.

${ }^{a)}$ Significant at $\mathrm{P}<0.05$ (two-tailed). ${ }^{\mathrm{b}} \mathrm{P}$-value was calculated using the Fisher exact test. ${ }^{\mathrm{C} P} \mathrm{P}$-value was calculated using the independent $\mathrm{t}$ test.

AOR, 8.84; $95 \% \mathrm{Cl}, 3.18$ to $24.61 ; \mathrm{P}<0.001)$, and VFT/SCFT $>2.9$ (crude $O R, 7.07 ; 95 \% \mathrm{Cl}, 2.54$ to 19.73; $\mathrm{P}<0.001 ; A O R, 9.39$; $95 \% \mathrm{Cl}, 2.97$ to $29.72 ; \mathrm{P}<0.001)$. Concerning the anthropometric measurements, participants with WHtR $>0.615$ had a risk of carotid artery atherosclerosis 3.34 times higher than those with WHtR $\leq 0.615$ (crude $O R, 3.34 ; 95 \% \mathrm{Cl}, 1.31$ to $8.29 ; \mathrm{P}=0.009$ ). In the multivariate analysis, this risk decreased to 2.65 times higher (AOR, 2.65; $95 \% \mathrm{Cl}, 1.02$ to $6.91 ; \mathrm{P}=0.046)$. In contrast, participants whose $\mathrm{HC}$ was $>105 \mathrm{~cm}$, relative to their counterparts whose $\mathrm{HC}$ was $\leq 105 \mathrm{~cm}$, showed a significant association in the univariate analysis, with a 2.9-fold increased risk of carotid artery atherosclerosis. However, after adjustment in the multivariate analysis, no significant association was detected (crude OR, 2.90; $95 \% \mathrm{Cl}, 1.18$ to $7.11 ; \mathrm{P}=0.020 ; \mathrm{AOR}, 2.29 ; 95 \% \mathrm{Cl}, 0.89$ to 5.86 ; $\mathrm{P}=0.082$ ). Other anthropometric indices showed no significant associations in both univariate and multivariate analyses.

Additionally, the results of univariate and multivariate regression analysis of possible indices predictive of carotid artery plaques were provided in Table 5. Regarding the abdominal fat indices, participants with PRPFT $>11.2 \mathrm{~mm}$ had a risk of carotid artery plaque that was 5.51 times higher than that of participants with PRPFT $\leq 11.2 \mathrm{~mm}$ (crude OR, 5.51; 95\% Cl, 2.15 to 14.22 ; 
Table 2. Statistical association between abdominal fat indices and anthropometric indices with carotid artery atherosclerosis $(\mathrm{n}=92)$

\begin{tabular}{lccr}
\hline \multicolumn{1}{c}{ Factor } & $\begin{array}{c}\text { IMT } \leq 0.9 \mathrm{~mm} \\
(\mathrm{n}=31)\end{array}$ & $\begin{array}{c}\text { IMT }>0.9 \mathrm{~mm} \\
(\mathrm{n}=61)\end{array}$ & P-value $^{\mathrm{a})}$ \\
\hline BMI $\left(\mathrm{kg} / \mathrm{m}^{2}\right)$ & $29.70 \pm 4.23$ & $30.01 \pm 3.34$ & 0.669 \\
WC $(\mathrm{cm})$ & $101.82 \pm 13.73$ & $106.52 \pm 8.55$ & 0.046 \\
HC $(\mathrm{cm})$ & $103.80 \pm 13.12$ & $110.43 \pm 10.11$ & 0.009 \\
WHR & $0.98 \pm 0.05$ & $0.97 \pm 0.05$ & 0.208 \\
WHtR & $0.62 \pm 0.08$ & $0.64 \pm 0.05$ & 0.061 \\
PRPFT $(\mathrm{mm})$ & $10.38 \pm 1.82$ & $12.91 \pm 1.55$ & $<0.001$ \\
SCFT $(\mathrm{mm})$ & $20.51 \pm 6.42$ & $22.72 \pm 4.01$ & 0.041 \\
PPFT $(\mathrm{mm})$ & $10.47 \pm 1.61$ & $11.91 \pm 1.59$ & $<0.001$ \\
VFT $(\mathrm{mm})$ & $55.28 \pm 15.91$ & $71.14 \pm 11.74$ & $<0.001$ \\
VFT $/ \mathrm{SCFT}$ & $2.78 \pm 0.62$ & $3.15 \pm 0.29$ & $<0.001$ \\
VAT $\left(\mathrm{mm}{ }^{3}\right)$ & $159.53 \pm 30.35$ & $189.25 \pm 19.30$ & $<0.001$ \\
AFI & $0.58 \pm 0.13$ & $0.57 \pm 0.11$ & 0.885 \\
\hline Vall & & &
\end{tabular}

Values are presented as mean \pm SD.

IMT, intima-media thickness; BMI, body mass index; WC, waist circumference; HC, hip circumference; WHR, waist-to-hip ratio; WHtR, waist-to-height ratio; PRPFT, posterior right perinephric fat thickness; SCFT, subcutaneous fat thickness; PPFT, preperitoneal fat thickness; VFT, visceral fat thickness; VFT/SCFT, ratio of visceral fat thickness to subcutaneous fat thickness; VAT, visceral adipose tissue volume; AFI, abdominal wall fat index; SD, standard deviation.

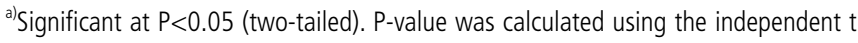
test.

$\mathrm{P}<0.001)$, and after adjustment in the multivariate analysis, this risk increased to 7.09 times higher (AOR, 7.09; 95\% Cl, 2.52 to 19.93; $\mathrm{P}<0.001)$. Additionally, participants with an $\mathrm{AFI}>0.519$ were at 3.22 times higher risk for the presence of carotid artery plaque than participants with an $\mathrm{AFI} \leq 0.519$ (crude OR, 3.22; $95 \% \mathrm{Cl}, 1.31$ to 7.95; $\mathrm{P}=0.011$ ), and after adjustment in the multivariate analysis, the risk increased to 3.58 times higher ( $A O R, 3.58 ; 95 \% \mathrm{Cl}, 1.36$ to 9.39; $\mathrm{P}=0.010$ ). Similarly, participants whose VFT/SCFT was $>2.9$ were at a 4.18 times higher risk for the presence of carotid artery plaque than participants whose VFT/SCFT was $\leq 2.9$ (crude OR, 4.18; $95 \% \mathrm{Cl}, 1.52$ to $11.53 ; \mathrm{P}=0.005)$; this $\mathrm{OR}$ was nearly unchanged by adjustment in the multivariate analysis (AOR, $4.17 ; 95 \% \mathrm{Cl}$, 1.52 to $11.41 ; \mathrm{P}=0.006)$. No other abdominal indices showed any significant associations with the presence of carotid artery plaque. Finally, none of the anthropometric indices showed any significant associations with the presence of carotid artery plaque.

\section{Discussion}

Many studies have shown that regional obesity is more closely associated with atherosclerosis than generalized obesity $[24,25]$.
Table 3. Statistical association between abdominal fat indices and anthropometric indices with carotid artery plaque $(n=92)$

\begin{tabular}{lccc}
\hline \multicolumn{1}{c}{ Factor } & $\begin{array}{c}\text { Absence of plaque } \\
(\mathrm{n}=42)\end{array}$ & $\begin{array}{c}\text { Presence of plaque } \\
(\mathrm{n}=50)\end{array}$ & P-value $^{\mathrm{a})}$ \\
\hline BMI $\left(\mathrm{kg} / \mathrm{m}^{2}\right)$ & $30.14 \pm 3.98$ & $29.71 \pm 3.36$ & 0.577 \\
WC $(\mathrm{cm})$ & $103.19 \pm 13.47$ & $106.34 \pm 7.68$ & 0.162 \\
HC $(\mathrm{cm})$ & $105.24 \pm 12.49$ & $110.61 \pm 10.23$ & 0.026 \\
WHR & $0.98 \pm 0.05$ & $0.96 \pm 0.05$ & 0.119 \\
WHtR & $0.63 \pm 0.08$ & $0.64 \pm 0.05$ & 0.704 \\
PRPFT $(\mathrm{mm})$ & $11.27 \pm 2.13$ & $12.72 \pm 1.71$ & $<0.001$ \\
SCFT $(\mathrm{mm})$ & $22.70 \pm 6.12$ & $21.37 \pm 3.89$ & 0.219 \\
PPFT $(\mathrm{mm})$ & $11.22 \pm 1.69$ & $11.59 \pm 1.76$ & 0.307 \\
VFT $(\mathrm{mm})$ & $64.54 \pm 18.93$ & $66.85 \pm 11.27$ & 0.471 \\
VFT $/ \mathrm{SCFT}$ & $2.87 \pm 0.58$ & $3.15 \pm 0.29$ & 0.004 \\
VAT $\left(\mathrm{mm}{ }^{3}\right)$ & $174.04 \pm 33.49$ & $183.64 \pm 20.22$ & 0.095 \\
AFI & $0.55 \pm 0.11$ & $0.59 \pm 0.11$ & 0.071 \\
\hline Vat & & & \\
\hline
\end{tabular}

Values are presented as mean \pm SD.

BMI, body mass index; WC, waist circumference; HC, hip circumference; WHR, waistto-hip ratio; WHtR, waist-to-height ratio; PRPFT, posterior right perinephric fat thickness; SCFT, subcutaneous fat thickness; PPFT, preperitoneal fat thickness; VFT, visceral fat thickness; VFT/SCFT, ratio of visceral fat thickness to subcutaneous fat thickness; VAT, visceral adipose tissue volume; AFI, abdominal wall fat index; SD, standard deviation.

${ }^{a)}$ Significant at $\mathrm{P}<0.05$ (two-tailed). $\mathrm{P}$-value was calculated using the independent $\mathrm{t}$ test.

The harmful effect of abdominal obesity arises from metabolic activity. Free fatty acids are released into the hepatic circulation with subsequent stimulation of the release of apolipoprotein B-containing lipoproteins, increasing the plasma glucose level and reducing insulin sensitivity. A number of cytokines released by adipose tissue may also be involved in the development of atherosclerosis [12].

The present study demonstrated significant associations between carotid atherosclerosis and SCFT, PRPFT, VAT, PPFT, VFT, and VFT/ SCFT. In contrast, the AFI showed a non-significant association with carotid artery atherosclerosis.

To further clarify and better assess the associations between the abdominal fat indices and carotid artery atherosclerosis, we performed univariate and multivariate analyses for all indices after choosing the best cutoff values via receiver operating curve (ROC) analysis. Regarding the abdominal fat indices, we detected that PPFT $>10.8 \mathrm{~mm}$, PRPFT $>11.2 \mathrm{~mm}, \mathrm{VFT}>62.1 \mathrm{~mm}, \mathrm{VFT} / \mathrm{SCFT}>2.9$, and VAT $>176$ were associated with increased risk of carotid artery atherosclerosis relative to their counterparts in both the univariate and multivariate analyses. In contrast, SCFT and the AFI showed non-significant associations with the presence of carotid artery atherosclerosis. Moreover, the current study revealed that PRPFT and 
Table 4. Univariate and multivariate analysis of ultrasonographic abdominal fat and anthropometric indices associated with carotid artery atherosclerosis $(n=92)$

\begin{tabular}{|c|c|c|c|c|c|c|}
\hline \multirow{2}{*}{ Factor } & \multicolumn{2}{|c|}{ No. (\%) } & \multirow{2}{*}{ Crude OR (95\% Cl) } & \multirow{2}{*}{ P-value ${ }^{a)}$} & \multirow{2}{*}{ Adjusted OR ${ }^{\mathrm{b})}(95 \% \mathrm{Cl})$} & \multirow{2}{*}{ P-value } \\
\hline & IMT $\leq 0.9(n=31)$ & IMT $>0.9(n=61)$ & & & & \\
\hline \multicolumn{7}{|c|}{ BMI level $\left(\mathrm{kg} / \mathrm{m}^{2}\right)$} \\
\hline$\leq 29.68$ & $15(48.4)$ & $24(39.3)$ & Ref & & Ref & \\
\hline$>29.68$ & $16(51.6)$ & $37(60.7)$ & $1.41(0.60-3.46)$ & 0.408 & $1.22(0.49-3.64)$ & 0.670 \\
\hline \multicolumn{7}{|l|}{ WC level (cm) } \\
\hline$\leq 103.0$ & $15(48.4)$ & $23(37.7)$ & Ref & & Ref & \\
\hline$>103.0$ & $16(51.6)$ & $38(62.3)$ & $1.55(0.65-3.71)$ & 0.327 & $1.39(0.11-0.89)$ & 0.482 \\
\hline \multicolumn{7}{|l|}{ HC level (cm) } \\
\hline$\leq 105.0$ & $17(54.8)$ & $18(29.5)$ & Ref & & Ref & \\
\hline$>105.0$ & $14(45.2)$ & $43(70.5)$ & $2.90(1.18-7.11)$ & 0.020 & $2.29(0.89-5.86)$ & 0.082 \\
\hline \multicolumn{7}{|l|}{ WHR level } \\
\hline$\leq 0.97$ & $13(44.8)$ & $31(51.7)$ & Ref & & Ref & \\
\hline$>0.97$ & $16(55.2)$ & $29(48.3)$ & $0.76(0.31-1.85)$ & 0.546 & $0.79(0.31-2.04)$ & 0.639 \\
\hline \multicolumn{7}{|l|}{ WHtR level } \\
\hline$\leq 0.615$ & $17(54.8)$ & $16(26.7)$ & Ref & & Ref & \\
\hline$>0.615$ & $14(45.2)$ & $44(73.3)$ & $3.34(1.31-8.29)$ & 0.009 & $2.65(1.02-6.90)$ & 0.046 \\
\hline \multicolumn{7}{|c|}{ PRPFT level (mm) } \\
\hline$\leq 11.2$ & $23(74.2)$ & $9(14.8)$ & Ref & & Ref & \\
\hline$>11.2$ & $8(25.8)$ & $52(85.2)$ & $16.62(5.69-48.53)$ & $<0.001$ & $15.23(4.99-46.24)$ & $<0.001$ \\
\hline \multicolumn{7}{|c|}{ SCFT level (mm) } \\
\hline$\leq 21.3$ & $16(51.6)$ & $15(24.6)$ & Ref & & Ref & \\
\hline$>21.3$ & $15(48.4)$ & $46(75.4)$ & $3.27(1.31-8.16)$ & 0.011 & $2.59(0.99-6.81)$ & 0.053 \\
\hline \multicolumn{7}{|c|}{ PPFT level (mm) } \\
\hline$\leq 10.8$ & 19 (61.3) & $16(26.2)$ & Ref & & Ref & \\
\hline$>10.8$ & $12(38.7)$ & $45(73.8)$ & $4.45(1.77-11.21)$ & 0.001 & $4.31(1.67-11.12)$ & 0.003 \\
\hline \multicolumn{7}{|c|}{ VAT level $\left(\mathrm{mm}^{3}\right)$} \\
\hline$\leq 176$ & $20(64.5)$ & $11(18.0)$ & Ref & & Ref & \\
\hline$>176$ & $11(35.5)$ & $50(82.0)$ & $8.26(3.09-22.12)$ & $<0.001$ & $7.61(2.70-21.43)$ & $<0.001$ \\
\hline \multicolumn{7}{|l|}{ AFI level } \\
\hline$\leq 0.519$ & $13(41.9)$ & $18(29.5)$ & Ref & & Ref & \\
\hline$>0.519$ & $18(58.1)$ & $43(70.5)$ & $1.72(0.70-4.25)$ & 0.235 & $2.84(0.99-8.08)$ & 0.051 \\
\hline \multicolumn{7}{|l|}{ VFT level (mm) } \\
\hline$\leq 62.1$ & $22(71.0)$ & $12(19.7)$ & Ref & & Ref & \\
\hline$>62.1$ & $9(29.0)$ & $49(80.3)$ & $9.98(3.67-27.12)$ & $<0.001$ & $8.84(3.18-24.61)$ & $<0.001$ \\
\hline \multicolumn{7}{|l|}{ VFT/SCFT } \\
\hline$\leq 2.9$ & $16(51.6)$ & $8(13.1)$ & Ref & & Ref & \\
\hline$>2.9$ & $15(48.4)$ & $53(86.9)$ & $7.07(2.54-19.73)$ & $<0.001$ & $9.39(2.97-29.72)$ & $<0.001$ \\
\hline
\end{tabular}

IMT, intima-media thickness; OR, odds ratio; Cl, confidence interval; BMI, body mass index; WC, waist circumference; HC, hip circumference; WHR, waist-to-hip ratio; WHtR, waist-to-height ratio; PRPFT, posterior right perinephric fat thickness; SCFT, subcutaneous fat thickness; PPFT, preperitoneal fat thickness; VAT, visceral adipose tissue volume; $\mathrm{AFI}$, abdominal wall fat index; VFT, visceral fat thickness; VFT/SCFT, ratio of visceral fat thickness to subcutaneous fat thickness.

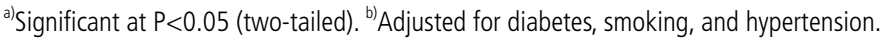


Table 5. Univariate and multivariate analysis of indices predicting carotid artery plaques

\begin{tabular}{|c|c|c|c|c|c|c|}
\hline \multirow[b]{2}{*}{ Factor } & \multicolumn{2}{|c|}{ No. (\%) } & \multirow[b]{2}{*}{ Crude OR (95\% Cl) } & \multirow[b]{2}{*}{ P-value ${ }^{a)}$} & \multirow[b]{2}{*}{ Adjusted $\mathrm{OR}^{\mathrm{b})}(95 \% \mathrm{Cl})$} & \multirow[b]{2}{*}{ P-value ${ }^{a)}$} \\
\hline & $\begin{array}{l}\text { Absence of plaque } \\
(n=42)\end{array}$ & $\begin{array}{l}\text { Presence of plaque } \\
\qquad(\mathrm{n}=50)\end{array}$ & & & & \\
\hline \multicolumn{7}{|c|}{ BMl level $\left(\mathrm{kg} / \mathrm{m}^{2}\right)$} \\
\hline$\leq 29.68$ & $15(35.7)$ & $24(48.0)$ & Ref & & Ref & \\
\hline$>29.68$ & $27(64.3)$ & $26(52.0)$ & $0.60(0.26-1.39)$ & 0.236 & $0.59(0.25-1.41)$ & 0.241 \\
\hline$>103.0$ & $21(50.0)$ & $33(66.0)$ & $1.94(0.84-4.50)$ & 0.122 & $2.04(0.85-4.92)$ & 0.111 \\
\hline \multicolumn{7}{|c|}{ HC level (cm) } \\
\hline$\leq 105.0$ & $19(45.2)$ & $16(32.0)$ & Ref & & Ref & \\
\hline$>105.0$ & $23(54.8)$ & $34(68.0)$ & $1.76(0.75-4.11)$ & 0.194 & $1.90(0.78-4.67)$ & 0.160 \\
\hline \multicolumn{7}{|l|}{ WHtR level } \\
\hline$\leq 0.615$ & $18(43.9)$ & $15(30.0)$ & Ref & & Ref & \\
\hline$>0.615$ & $23(56.1)$ & $35(70.0)$ & $1.83(0.77-4.33)$ & 0.172 & $0.51(0.20-1.27)$ & 0.147 \\
\hline \multicolumn{7}{|c|}{ PRPFT level (mm) } \\
\hline$\leq 11.2$ & $23(54.8)$ & $9(18.0)$ & Ref & & Ref & \\
\hline$>11.2$ & $19(45.2)$ & $41(82.0)$ & $5.51(2.15-14.22)$ & $<0.001$ & $7.09(2.52-19.93)$ & $<0.001$ \\
\hline \multicolumn{7}{|c|}{ SCFT level (mm) } \\
\hline$\leq 21.3$ & $14(33.3)$ & $17(34.0)$ & Ref & & Ref & \\
\hline$>176$ & $24(57.1)$ & $37(74.0)$ & $2.13(0.89-5.14)$ & 0.091 & $2.36(0.93-5.95)$ & 0.070 \\
\hline \multicolumn{7}{|l|}{ AFI level } \\
\hline$\leq 0.519$ & $20(47.6)$ & $11(22.0)$ & Ref & & Ref & \\
\hline$>0.519$ & $22(52.4)$ & $39(78.0)$ & $3.22(1.31-7.95)$ & 0.011 & $3.58(1.36-9.39)$ & 0.010 \\
\hline \multicolumn{7}{|c|}{ VFT level (mm) } \\
\hline$\leq 62.1$ & $19(45.2)$ & $15(30.0)$ & Ref & & Ref & \\
\hline$>62.1$ & $23(54.8)$ & $35(70.0)$ & $1.93(0.82-4.54)$ & 0.134 & $2.06(0.84-5.05)$ & 0.113 \\
\hline \multicolumn{7}{|l|}{ VFT/SCFT } \\
\hline$\leq 2.9$ & $17(40.5)$ & $7(14.0)$ & Ref & & Ref & \\
\hline$>2.9$ & $25(59.5)$ & $43(86.0)$ & $4.18(1.52-11.53)$ & 0.005 & $4.17(1.52-11.41)$ & 0.006 \\
\hline
\end{tabular}

OR, odds ratio; $\mathrm{Cl}$, confidence interval; BMI, body mass index; WC, waist circumference; HC, hip circumference; WHR, waist-to-hip ratio; WHtR, waist-to-height ratio; PRPFT, posterior right perinephric fat thickness; SCFT, subcutaneous fat thickness; PPFT, preperitoneal fat thickness; VAT, visceral adipose tissue volume; AFI, abdominal wall fat index; VFT, visceral fat thickness; VFT/SCFT, ratio of visceral fat thickness to subcutaneous fat thickness.

${ }^{a}$ Significant at $\mathrm{P}<0.05$ (two-tailed). ${ }^{\text {b) } A d j u s t e d ~ f o r ~ d i a b e t e s, ~ s m o k i n g, ~ a n d ~ h y p e r t e n s i o n . ~}$ 
VFT/SCFT were significantly associated with the presence of carotid plaque. After selecting the best cutoff values using ROC analysis, we performed univariate and multivariate analyses. From the abdominal fat indices, we detected that PRPFT $>11.2 \mathrm{~mm}, \mathrm{AFI}>0.519 \mathrm{~mm}$, and VFT/SCFT $>2.9$ were associated with increased risk of carotid artery plaque relative to their counterparts in both the univariate and multivariate analyses. In contrast, SCFT, PPFT, VAT, and VFT showed non-significant associations with the presence of carotid artery plaque.

To the best of our knowledge, few studies are available regarding the association between the posterior perinephric fat and carotid atherosclerosis in adults; our results align with results obtained by Liu et al. [11], who suggested that perirenal fat is a promising target for cardiovascular disease management. Moreover, Roever et al. [20] reported that PRPFT may be useful in identifying individuals with an elevated risk of developing atherosclerotic disease. Our findings are also in accordance with the results obtained by Rallidis et al. [17], who compared VAT and WC as predictors of subclinical atherosclerosis and concluded that only VAT was positively correlated with IMT and remained an independent predictor of carotid artery plaque after adjustment for cardiovascular risk factors. However, in contrast to our results, they found that WC could be used as a predictor of the presence of carotid plaque. Lear et al. [12] concluded that VAT was associated with carotid IMT in women and men, but after adjustment for risk factors, this relationship remained significant for men only.

With regard to VFT and VFT/SCFT, our results align with those obtained by Kim et al. [26]. Those researchers found a similar association between VFT and carotid IMT, both of which were measured via ultrasonography [26]. However, our findings do not agree with the results obtained by Jung et al. [18], who found that VFT and VFT/SCFT were not significantly correlated with IMT in women or men. Regarding the AFI, our results are in accordance with those obtained by Yamamoto et al. [27], who found that the AFI was not correlated with IMT. However, our findings contradict the results obtained by Kawamoto et al. [19], as they detected an association between IMT and the AFI, rather than maximum PPFT, in non-obese men. Kawamoto et al. [28] considered the AFI to be an independent risk factor for IMT in women.

Considerable disagreement exists regarding whether SCFT is a good predictor of carotid atherosclerosis. In contrast to our results, Jung et al. [18] demonstrated that SCFT was inversely associated with carotid IMT after adjustments for BMI and other traditional or non-traditional cardiovascular disease risk factors in men, but not in women. However, our results align with those of Radmard et al. [13], who concluded that subcutaneous fat measures were poor indicators of carotid IMT.
We detected a strong association between PPFT and carotid atherosclerosis, in accordance with findings obtained by Yamamoto et al. [27], who proposed that PPFT, as assessed via ultrasonography, may play a role in the progression of IMT in middle-aged non-obese men. Our results agree with those obtained by Kawamoto et al. [29], in which PPFT assessed via ultrasonography was found to be an important risk factor for carotid IMT, but they contradict findings obtained by Liu et al. [30] In that report, no significant association was detected in men; in the univariate analysis, borderline statistical significance was detected in women, but it disappeared after adjustment of the model.

In contrast, of the anthropometric measurements, only HC showed a strong association with carotid atherosclerosis. WC showed a weak association. After choosing the best cutoff value via ROC analysis, we performed univariate and multivariate analyses for all indices. Of all anthropometric indices, we detected that an HC $>105 \mathrm{~mm}$ increased the risk of carotid artery atherosclerosis in the univariate analysis, but after adjustment in the multivariate analysis, this significance was lost. However, participants with WHtR $>0.615$ demonstrated increased risk of carotid artery atherosclerosis in both the univariate and multivariate analyses. Other anthropometric indices showed no significant associations.

Controversy persists regarding anthropometric indices as predictors of carotid atherosclerosis. Radmard et al. [13] reported that WHtR, BMI, and WHR were not good predictors for the presence of carotid atherosclerosis. Moreover, Lee et al. [31] revealed that $\mathrm{BMI}$ is a poor discriminator for cardiovascular risk factors, and Rallidis et al. [17] reported that BMI could not be used to predict the presence of carotid plaques. However, Hsieh and Yoshinaga [32] reported that WHtR was the tool with the best discrimination for detecting cardiovascular risk factor. Additionally, Rallidis et al. [17] reported that WC could be used as a predictor of carotid plaques only in the univariate analysis. De Michele et al. [4] concluded that WHR and BMI were significant predictors of carotid IMT.

In our study, we noticed a discrepancy between our results and previous findings; this could be partially due to the influence of ethnic differences on the intra-abdominal fat distribution.

The current study had some limitations. First, we included a relatively small number of patients, although we did include several abdominal fat and anthropometric indices and assessed their associations with carotid atherosclerosis. To the best of our knowledge, few papers have been published regarding associations between posterior perinephric fat thickness and carotid atherosclerosis. Furthermore, an important aspect of our research was the use of cutoff values to determine the risk for each index. Second, it is possible that our results may have been biased by the patient population, because the patients were referred randomly 
from outpatient internal medicine clinics. Several risk factors are associated with carotid atherosclerosis, and many of these factors show clinical overlap and could be present in the same patient. Third, MRI and CT are superior imaging modalities for the measurement of abdominal fat areas, but limited availability, high cost, and the hazards of ionizing radiation limit their usage. Therefore, we used ultrasonography in our assessment because of its accuracy relative to $\mathrm{CT}$ and MRI, availability, cost-effectiveness, and high safety profile. Finally, we only measured carotid IMT as a marker of carotid atherosclerosis. We did not assess other carotid atherosclerotic values, including pulse wave velocity and arterial elasticity.

In conclusion, posterior perinephric fat thickness as measured via ultrasound was found to be a strong predictor of carotid atherosclerosis, followed by VFT/SCFT, VFT, VAT, PPFT, and WHtR with regard to predictive capacity. Additionally, posterior perinephric fat thickness was identified as a strong predictor for carotid artery plaque, followed by VFT/SCFT and the AFI.

ORCID: Mohammed Hazem: https://orcid.org/0000-0003-1138-9413; Mahmoud Elsamman: https://orcid.org/0000-0002-9212-8954; Shamardan Bazeed: https:// orcid.org/0000-0001-7653-0006; Mohammed Zaki: https://orcid.org/0000-00020413-5055

\section{Author Contributions}

Conceptualization: Hazem M, Elsamman M. Data acquisition: Hazem M, Elsamman M. Data analysis or interpretation: Hazem M, Bazeed S. Drafting of the manuscript: Bazeed S, Zaki M. Critical revision of the manuscript: Hazem M, Elsamman M, Zaki M. Approval of the final version of the manuscript: all authors.

\section{Conflict of Interest}

No potential conflict of interest relevant to this article was reported.

\section{References}

1. Haberka M, Skilton M, Biedroń M, Szóstak-Janiak K, Partyka M, Matla M, et al. Obesity, visceral adiposity and carotid atherosclerosis. J Diabetes Complications 2019;33:302-306.

2. U-King-Im JM, Young V, Gillard JH. Carotid-artery imaging in the diagnosis and management of patients at risk of stroke. Lancet Neurol 2009;8:569-580

3. Simova I. Intima-media thickness: appropriate evaluation and proper measurement. E-journal Cardiol Pract 2015;13(21).

4. De Michele M, Panico S, lannuzzi A, Celentano E, Ciardullo AV, Galasso R, et al. Association of obesity and central fat distribution with carotid artery wall thickening in middle-aged women. Stroke
2002;33:2923-2928.

5. Maher V, O'Dowd M, Carey M, Markham C, Byrne A, Hand E, et al. Association of central obesity with early Carotid intima-media thickening is independent of that from other risk factors. Int J Obes (Lond) 2009;33:136-143.

6. DeMarco VG, Aroor AR, Sowers JR. The pathophysiology of hypertension in patients with obesity. Nat Rev Endocrinol 2014;10:364-376.

7. Klein S. The case of visceral fat: argument for the defense. J Clin Invest 2004;113:1530-1532.

8. Lim S, Meigs JB. Links between ectopic fat and vascular disease in humans. Arterioscler Thromb Vasc Biol 2014;34:1820-1826.

9. Chau YY, Bandiera R, Serrels A, Martínez-Estrada OM, Qing W, Lee $M$, et al. Visceral and subcutaneous fat have different origins and evidence supports a mesothelial source. Nat Cell Biol 2014;16:367375.

10. De Pergola G, Campobasso N, Nardecchia A, Triggiani V, Caccavo D, Gesualdo $L$, et al. Para- and perirenal ultrasonographic fat thickness is associated with 24-hours mean diastolic blood pressure levels in overweight and obese subjects. BMC Cardiovasc Disord 2015; 15:108

11. Liu BX, Sun W, Kong XQ. Perirenal fat: a unique fat pad and potential target for cardiovascular disease. Angiology 2019;70:584593.

12. Lear $\mathrm{SA}$, Humphries $\mathrm{KH}$, Kohli S, Frohlich JJ, Birmingham $\mathrm{CL}$, Mancini GB. Visceral adipose tissue, a potential risk factor for carotid atherosclerosis: results of the Multicultural Community Health Assessment Trial (M-CHAT). Stroke 2007;38:2422-2429.

13. Radmard AR, Poustchi $H$, Ansari L, Khorasanizadeh F, Yoonessi A, Hashemi Taheri AP, et al. Abdominal fat distribution and carotid atherosclerosis in a general population: a semi-automated method using magnetic resonance imaging. Jpn J Radiol 2016;34:414-422.

14. Gast KB, Smit JW, den Heijer M, Middeldorp S, Rippe RC, le Cessie $S$, et al. Abdominal adiposity largely explains associations between insulin resistance, hyperglycemia and subclinical atherosclerosis: the NEO study. Atherosclerosis 2013;229:423-429.

15. Recio-Rodriguez JI, Gomez-Marcos MA, Patino-Alonso MC, AgudoConde C, Rodriguez-Sanchez E, Garcia-Ortiz L. Abdominal obesity vs general obesity for identifying arterial stiffness, subclinical atherosclerosis and wave reflection in healthy, diabetics and hypertensive. BMC Cardiovasc Disord 2012;12:3.

16. Yan RT, Yan AT, Anderson TJ, Buithieu J, Charbonneau F, Title L, et al. The differential association between various anthropometric indices of obesity and subclinical atherosclerosis. Atherosclerosis 2009;207:232-238.

17. Rallidis LS, Baroutsi K, Zolindaki M, Karagianni M, Varounis C, Dagres $\mathrm{N}$, et al. Visceral adipose tissue is a better predictor of subclinical carotid atherosclerosis compared with waist circumference. Ultrasound Med Biol 2014;40:1083-1088. 
18. Jung $\mathrm{CH}$, Kim BY, Kim KJ, Jung SH, Kim CH, Kang SK, et al. Contribution of subcutaneous abdominal fat on ultrasonography to carotid atherosclerosis in patients with type 2 diabetes mellitus. Cardiovasc Diabetol 2014;13:67.

19. Kawamoto R, Oka Y, Tomita H, Kodama A, Ootsuka N. Association between abdominal wall fat index on ultrasonography and carotid atherosclerosis in non-obese men. J Atheroscler Thromb 2005; 12:85-91.

20. Roever L, Resende ES, Veloso FC, Diniz AL, Penha-Silva N, CasellaFilho $A$, et al. Perirenal fat and association with metabolic risk factors: the Uberlândia Heart Study. Medicine (Baltimore) 2015;94:e1105.

21. Roever LS, Resende ES, Diniz AL, Penha-Silva N, Veloso FC, Casella-Filho $A$, et al. Abdominal obesity and association with atherosclerosis risk factors: the Uberlândia Heart Study. Medicine (Baltimore) 2016;95:e1357.

22. Hirooka M, Kumagi T, Kurose K, Nakanishi S, Michitaka K, Matsuura $B$, et al. A technique for the measurement of visceral fat by ultrasonography: comparison of measurements by ultrasonography and computed tomography. Intern Med 2005;44:794-799.

23. Williams B, Mancia G, Spiering W, Agabiti Rosei E, Azizi M, Burnier $M$, et al. 2018 ESC/ESH Guidelines for the management of arterial hypertension. Eur Heart J 2018;39:3021-3104.

24. Blüher M. Adipose tissue dysfunction in obesity. Exp Clin Endocrinol Diabetes 2009;117:241-250.

25. Divers J, Wagenknecht LE, Bowden DW, Carr JJ, Hightower RC, Ding J, et al. Regional adipose tissue associations with calcified atherosclerotic plaque: African American-diabetes heart study. Obesity (Silver Spring) 2010;18:2004-2009.

26. Kim SK, Park SW, Kim SH, Cha BS, Lee HC, Cho YW. Visceral fat amount is associated with carotid atherosclerosis even in type 2 diabetic men with a normal waist circumference. Int J Obes (Lond) 2009;33:131-135.

27. Yamamoto M, Egusa G, Hara H, Yamakido M. Association of intraabdominal fat and carotid atherosclerosis in non-obese middle-aged men with normal glucose tolerance. Int J Obes Relat Metab Disord 1997;21:948-951.

28. Kawamoto R, Kajiwara T, Oka Y, Takagi Y. Association between abdominal wall fat index and carotid atherosclerosis in women. J Atheroscler Thromb 2002;9:213-218.

29. Kawamoto R, Ohtsuka N, Ninomiya D, Nakamura S. Association of obesity and visceral fat distribution with intima-media thickness of carotid arteries in middle-aged and older persons. Intern Med 2008;47:143-149.

30. Liu KH, Chan YL, Chan JC, Chan WB. Association of carotid intimamedia thickness with mesenteric, preperitoneal and subcutaneous fat thickness. Atherosclerosis 2005; 179:299-304.

31. Lee CM, Huxley RR, Wildman RP, Woodward M. Indices of abdominal obesity are better discriminators of cardiovascular risk factors than BMI: a meta-analysis. J Clin Epidemiol 2008;61:646653.

32. Hsieh SD, Yoshinaga $H$. Waist/height ratio as a simple and useful predictor of coronary heart disease risk factors in women. Intern Med 1995;34:1147-1152. 